\title{
Implications of long-term culture for mesenchymal stem cells: genetic defects or epigenetic regulation?
}

\author{
Wolfgang Wagner* \\ See related research by Redaelli et al., http://stemcellres.com/content/3/6/47
}

\begin{abstract}
Mesenchymal stem cells change dramatically during culture expansion. Long-term culture has been suspected to evoke oncogenic transformation: overall, the genome appears to be relatively stable throughout culture but transient clonal aneuploidies have been observed. Oncogenic transformation does not necessarily entail growth advantage in vitro and, therefore, the available methods - such as karyotypic analysis or genomic profiling - cannot exclude this risk. On the other hand, long-term culture is associated with specific senescence-associated DNA methylation (SA-DNAm) changes, particularly in developmental genes. SA-DNAm changes are highly reproducible and can be used to monitor the state of senescence for quality control. Notably, neither telomere attrition nor SA-DNAm changes occur in pluripotent stem cells, which can evade the 'Hayflick limit'. Long-term culture of mesenchymal stem cells seems to involve a tightly regulated epigenetic program. These epigenetic modifications may counteract dominant clones, which are more prone to transformation.
\end{abstract}

\section{Genetic or epigenetic changes during culture expansion?}

Mesenchymal stem cells (MSCs) require culture-expansion to achieve sufficient cell numbers, particularly for therapeutic applications. Long-term culture, however, is associated with extensive morphological and functional changes, such as loss of in vitro differentiation potential.

*Correspondence: wwagner@ukaachen.de

Helmholtz-Institute for Biomedical Technology, Stem Cell Biology and Cellular Engineering, RWTH Aachen University Medical School, Pauwelsstrasse 20, 52074 Aachen, Germany
These changes are continuously acquired and conflict with the high demands for standardization and safety in regenerative medicine. Cells in culture may accumulate stochastic mutations, thus bearing the risk of malignant transformation. Furthermore, MSCs acquire specific epigenetic changes during culture, which may account for the functional changes. For a better understanding of this process, Redaelli and coworkers [1] have recently compared genetic and epigenetic modifications in the course of culture expansion of MSCs.

\section{The risk of malignant transformation: an unmet challenge in cellular therapy}

So far, oncogenic transformation of MSCs has not been observed despite their extensive application in a wide variety of clinical trials. Two publications reported spontaneous transformation of MSCs with tumor formation in immunocompromised mice - but both were subsequently retracted as the results were based on contamination with immortalized cell lines [2,3]. The concerns, however, still remain: expansion of MSCs is associated with enormous proliferation rates in an artificial cell culture environment and it is well conceivable that this favors genetic defects. Particularly autologous transplant settings appear to be prone to transplant-associated tumor formation because potentially transformed cells would be less challenged by the immune system. In fact, several studies reported occasional existence of transient aneuploidy in MSCs but cells with abnormal karyotype did not persist $[1,4]$ : these were lost upon prolonged culture and all MSC preparations ultimately entered senescence with proliferation arrest. Array-comparative genomic hybridization has been used in search of smaller deletions or duplications $[1,5,6]$. However, this method only detects dominant cell clones, which account for a significant percentage of the entire cell population. Yet oncogenic transformation is not necessarily associated with growth-advantage in vitro. Furthermore, point mutations or other subtle molecular events might also 


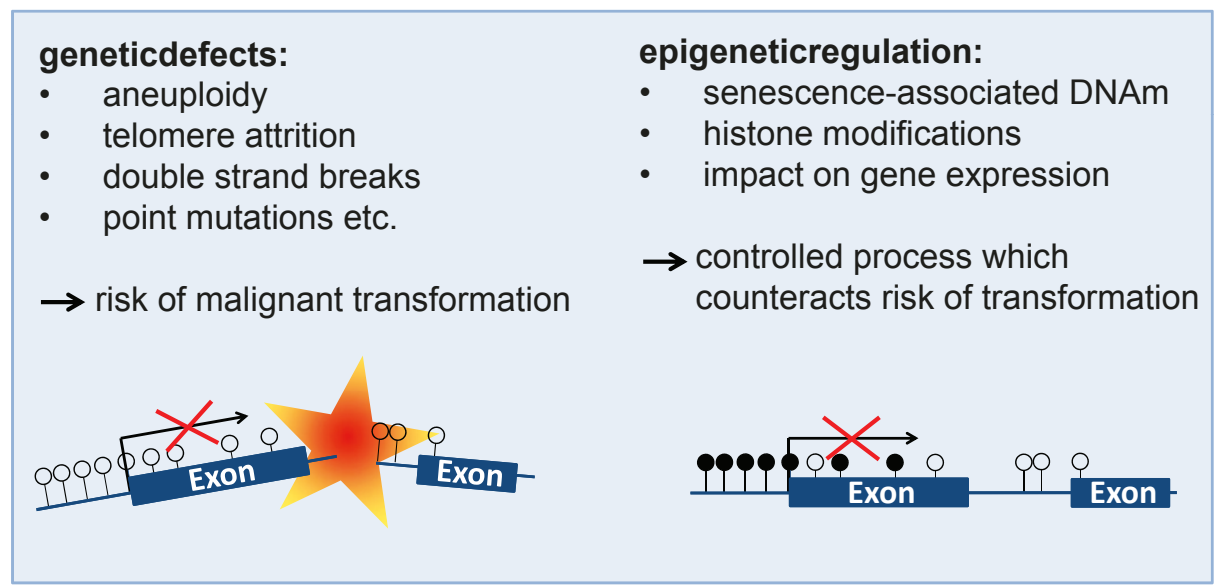

Figure 1. Molecular changes upon long-term culture of mesenchymal stem cells. DNAm, DNA methylation.

predispose to transformation. Therefore, the available methods for karyotypic analysis and genomic profiling cannot exclude the risk of transplant-associated tumor formation.

\section{Epigenetic changes during culture expansion}

Epigenetic modifications, such as DNA methylation (DNAm) and histone modification, play pivotal roles in the development, cellular differentiation and aging of the organism. They may also be relevant for functional changes during long-term culture of MSCs: specific CpG sites, particularly in developmental genes and homeobox genes, become differentially methylated at higher passages $[1,5,7,8]$. These senescence-associated DNAm (SA-DNAm) changes are extremely reproducible in different cell preparations and an 'Epigenetic-Senescence-Signature' can be used to monitor senescence for quality control [9]. SA-DNAm changes are enriched in intergenic regions and seem to be associated with repressive histone marks such as H3K9, H3K27 and polycomb-group protein targets [5,7]. These results indicate that long-term culture of MSCs is associated with a tightly regulated epigenetic program.

\section{Senescence is not an inevitable fate - it may be advantageous}

Cellular senescence is not an inevitable fate of all cells in culture: pluripotent cells, such as embryonic stem cells and induced pluripotent stem cells, can bypass the 'Hayflick limit' [10]. Their telomeres refrain from attrition. Notably, embryonic stem cells and induced pluripotent stem cells escape also from SA-DNAm changes [7]. Apparently, these primitive cells can be rejuvenated to grant their specific function for the organism. On the other hand, the barrier of senescence in somatic cells may be purposeful to reduce the risk of oncogenic trans- formation - it limits expansion of dominant and potentially malignant cells (Figure 1).

\section{Conclusion}

The genome of MSCs appears to be relatively stable throughout culture and so far malignant transformation upon MSC transplantation has not been observed in clinical trials. However, the fear of transplant-associated tumor formation still remains and it cannot be ruled out by the available molecular methods. On the other hand, long-term culture of MSCs induces tightly regulated epigenetic modifications. It is yet unclear how this process is regulated, but its purpose might be growth restriction of dominant clones - such as the transient clones with aneuploidy. Such dominant clones may acquire SADNAm changes faster than others and consequently disappear from culture due to enhanced senescence. Epigenetic changes might therefore antagonize some of the genetic defects during long-term culture of MSCs.

\section{Abbreviations}

DNAm, DNA methylation; MSC, mesenchymal stem cell; SA-DNAm, senescence-associated DNAm.

\section{Competing interests}

RWTH Aachen has submitted a patent application for the 'EpigeneticSenescence-Signature'. The author declares that he has no other competing interests.

\section{Acknowledgements}

This work was supported by the German Research Foundation (DFG; WA1706/2-1 and WA1706/3-1), by the Else-Kröner-Fresenius Stiftung, and by the Stem Cell Network NRW.

Published: 20 December 2012

\section{References}

1. Redaelli S, Bentivegna A, Foudah D, Miloso M, Redondo J, Riva G, Baronchelli S, Dalpra L, Tredici G: From cytogenomic to epigenomic profiles: monitoring the biological behavior of in vitro cultured human bone marrow mesenchymal stem cells. Stem Cell Res Ther 2012, 3:47. 
2. Garcia S, Bernad A, Martin MC, Cigudosa JC, Garcia-Castro J, de la FR: Pitfalls in spontaneous in vitro transformation of human mesenchymal stem cells. Exp Cell Res 2010, 316:1648-1650.

3. Torsvik A, Røsland GV, Svendsen A, Molven A, Immervoll H, McCormack E, Lønning PE, Primon M, Sobala E, Tonn JC, Goldbrunner R, Schichor C, Mysliwietz J, Lah TT, Motaln H, Knappskog S, Bjerkvig R: Spontaneous malignant transformation of human mesenchymal stem cells reflects cross-contamination: putting the research field on track - letter. Cancer Res 2010, 70:6393-6396

4. Tarte K, Gaillard J, Lataillade JJ, Fouillard L, Becker M, Mossafa H, Tchirkov A, Rouard H, Henry C, Splingard M, Dulong J, Monnier D, Gourmelon P, Gorin NC, Sensebé L; Société Française de Greffe de Moelle et Thérapie Cellulaire: Clinical-grade production of human mesenchymal stromal cells: occurrence of aneuploidy without transformation. Blood 2010, 115:1549-1553.

5. Schellenberg A, Lin Q, Schueler H, Koch C, Joussen S, Denecke B, Walenda G, Pallua N, Suschek C, Zenke M, Wagner W: Replicative senescence of mesenchymal stem cells causes DNA-methylation changes which correlate with repressive histone marks. Aging (Albany NY) 2011, 3:873-888.

6. Bernardo ME, Zaffaroni N, Novara F, Cometa AM, Avanzini MA, Moretta A, Montagna D, Maccario R, Villa R, Daidone MG, Zuffardi O, Locatelli F: Human bone marrow derived mesenchymal stem cells do not undergo transformation after long-term in vitro culture and do not exhibit telomere maintenance mechanisms. Cancer Res 2007, 67:9142-9149.

7. Koch CM, Reck K, Shao K, Lin Q, Joussen S, Ziegler P, Walenda G, Drescher W, Opalka B, May T, Brummendorf TH, Zenke M, Saric T, Wagner W: Pluripotent stem cells escape from senescence-associated DNA methylation changes. Genome Res 2012 [Epub ahead of print].

8. Bork S, Pfister S, Witt H, Horn P, Korn B, Ho AD, Wagner W: DNA methylation pattern changes upon long-term culture and aging of human mesenchymal stromal cells. Aging Cell 2010, 9:54-63.

9. Koch CM, Joussen S, Schellenberg A, Lin Q, Zenke M, Wagner W: Monitoring of Cellular Senescence by DNA-Methylation at Specific $\mathrm{CpG}$ sites. Aging Cell 2012, 11:366-369.

10. Lapasset L, Milhavet O, Prieur A, Besnard E, Babled A, Ait-Hamou N, Leschik J, Pellestor F, Ramirez JM, De VJ, Lehmann S, Lemaitre JM: Rejuvenating senescent and centenarian human cells by reprogramming through the pluripotent state. Genes Dev 2011, 25:2248-2253.

\section{doi:10.1186/scrt145}

Cite this article as: Wagner W: Implications of long-term culture for mesenchymal stem cells: genetic defects or epigenetic regulation? Stem Cell Research \& Therapy 2012, 3:54 